\title{
Simulation on the Channeling Flow in Porous Media with Open-type Crack under Low Frequency Vibration
}

\author{
Liming Zheng ${ }^{*}$ Jie Fan, Lianjin Wang, Qingzhong Chu and Xinjun Yang \\ College of Vehicles and Energy in Yanshan University, Qinhuangdao, Hebei 066004, China
}

${ }^{*}$ Corresponding author

Keywords: Low frequency wave, Dual porous media, Open-type crack, Seepage, Channeling rate.

\begin{abstract}
The application of wave stimulation technology in low permeability reservoirs with natural cracks was involved with the coupling of wave-induced flow, initial flow and solid deformation during the wave propagation process. Researchers had much work on the mechanism of seepage variation in dual porous media with constant permeability crack. However, the natural crack might be open-type some time, of which the width could increase with fluid pressure. The seepage in dual porous media under wave impact became more complicated. Thereby, a mathematic model about the seepage in porous media with open-type crack under low frequency vibration excitation was established. A comparison on the variation of channeling flow between matrix and crack was made before and after low frequency wave stimulation. The influence of a coefficient in the above empirical relationship on channeling flow rate was analyzed. It was found that the channeling rate (4-6 times with the simulation parameters) and permeability of open-type crack in dual porous media had both increased after the impact of low frequency vibration. The stimulation effect decreased gradually with the attenuation of wave. The easier the crack was to open, the stronger the variation of crack permeability was.
\end{abstract}

\section{Introduction}

Natural cracks existed widely in low permeability reservoirs and the size of cracks differs from microns to several meters. One kind of the cracks could change from close-type to open-type with the increase of fluid pressure, and the width of open-type crack increased continually. The existence of open-type crack played a contradictory role in the development process of oil reservoir. On one hand, the open-type crack greatly improved the reservoir seepage capacity and water absorption capacity. On the other hand, with the increase of fluid pressure inner the crack, the natural crack might open, or semi open-type crack became fully-open type crack, forming generally connected channels with ultra-high permeability. Zhang et al.(2016) found that the fracture permeability increased significantly with increasing the injection pressure, resulting in faster water breakthrough and lower efficiency water flooding [1].

When the porous media with open-type cracks was impacted by low frequency vibration oil production technology, the fluid flow was coupling with strong matrix deformation and elastic wave propagation (Alexandre et al., 2006; Karve, Kallivokas and Manuel, 2017; He et al. 2018)[2-4]. When the shock intensity reached a certain level, the increased fluid pressure inner crack which was induced by elastic wave would lead to the change of fracture morphology. It might cause the fracture length to extend, or the width of crack changed obviously. Since, the researchers in petroleum development fields and in petro-physics had done much work on the seepage mechanics of dual porous media and the wave propagation rule in fractured porous media indecently, instead of considering the coupling effect. It was noted that the crack was assumed usually with constant width. Only a little literature about the seepage under wave in porous media open-type crack was found (Wang et al., 2018; Tong and Gao, 2018a, b)[5-7]. Considering the complex change of seepage field in dual porous media with open-type cracks under the influence of wave induced flow, it helped to understand the effect of low frequency vibration oil production technology in such reservoirs.

By coupling elastic wave propagation model of fractured porous media, the seepage model of dual porous media and an empirical relationship between crack width and fluid pressure, a mathematical 
model about the seepage in porous media with open-type crack under low frequency vibration excitation was established. A comparison on the variation of channeling flow between matrix and crack was made before and after low frequency wave stimulation. Finally, the influence of a coefficient in the above empirical relationship on channeling flow rate was analyzed.

\section{Mathematical Model}

The application of wave stimulation technology in dual porous media with open-type crack should consider the wave propagation and the seepage simultaneously. The wave induced flow was generated in the matrix pores and the relevant equations could referred to that of Biot (1956) and Dvorkin, Mavko and Nur (1995)[8-9]. It was assumed that Biot flow and squirt flow were induced in the matrix pores and only Biot flow was formed in the crack because of the difference in matrix permeability and crack permeability. The effective stiffness tensor of fractured porous media was influenced under low frequency wave stimulation, reffering to the Chapman model (Chapman, 2009)[10]. The channeling flow was referred to the Warren-Root model for a situation with relative high crack density. Single phase fluid was assumed saturated in dual porous media.

\section{Chapman Model}

The expression of the effective stiffness tensor of Chapman model was shown in Equation 1. Because Chapman model was suitable for a low porosity condition, a high error might be caused in a case of high porosity when calculating the stiffness tensor with the Lame coefficients of particles (Chapman, 2009).

$$
C=C^{0}-\phi_{m} C^{1}-\varepsilon_{c} C^{2}-\varepsilon_{f} C^{3},
$$

wherein, $C$ is the modulus matrix of porous media with cracks under vibration; $C^{0}$ is the elastic modulus matrix of rock skeleton (or rock matrix), which can be expressed by Lame coefficients; $\phi_{m}$ is the porosity of rock matrix; $C^{1}, C^{2}$, and $C^{3}$ is the additional contribution to modulus matrix from pore, micro crack and fracture, respectively, and they were related with Lame coefficients, fluid properties, fracture properties, vibration frequency as well as relaxation time related to squirt flow; $\varepsilon_{c}$ is the density of micro crack; $\varepsilon_{f}$ is the density of fracture.

\section{Warren-Root Model}

The continuity equations of solid phase and fluid phase were as in Equation (2) to (4),

$$
\begin{aligned}
& \operatorname{div}\left[\left(1-\phi_{m}-\phi_{f}\right) \rho_{s} \frac{\partial u}{\partial t}\right]+\frac{\partial}{\partial t}\left[\left(1-\phi_{m}-\phi_{f}\right) \rho_{s}\right]=0, \\
& \operatorname{div}\left[\rho_{m} \frac{\partial\left(w_{m}+\phi_{m} u\right)}{\partial t}\right]+\frac{\partial\left(\rho_{m} \phi_{m}\right)}{\partial t}+q^{*}=0, \\
& \operatorname{div}\left[\rho_{f} \frac{\partial}{\partial t}\left(w_{f}+\phi_{f} u\right)\right]+\frac{\partial\left(\rho_{f} \phi_{f}\right)}{\partial t}-q^{*}+q_{0}=0,
\end{aligned}
$$

wherein, $q_{0}$ is the source or sink term, representing the injection or production rate per unit volume of underground rock; $q^{*}$ is the channeling flow rate between crack and rock matrix.

Referring to the seepage mechanics of dual porous media, the channeling flow rate was as Equation (5), 


$$
q^{*}=\frac{\alpha_{\text {shape }} \rho_{m} k_{m}}{\eta}\left(P_{m}-P_{f}\right),
$$

wherein $\alpha_{\text {shape }}$ is the shape factor, and Lei(2014) found that Costs model approached the experimental result, $\alpha_{\text {shape }}=\frac{16}{L^{2}}$ in two dimensional situation[11]; $L$ is the average characteristic length of matrix cell as in Equation.

\section{Empirical Relationship between Crack Width and Pressure}

In the literature on fracture deformation, there were mainly two kinds of empirical equations, linear style $\left(d h_{f}=d P_{f} / K_{n}\right)$ and exponential style $\left(d h_{f} / h_{f}=\beta \cdot \alpha \phi_{f} d P_{f} / 3\right)$. Wherein $h_{f}$ is the crack width, $P_{f}$ is the fluid pressure in the crack, $K_{n}$ is a liner coefficient, $\beta$ is an exponential coefficient, and $\alpha$ is the effective strain factor. Comparatively, the exponential equation was found better correlated with the experimental variation of crack width (Zhang et al., 2016)[1].

Substituting the exponential empirical relationship about open-type crack width into a conventional formula of fracture porosity, the relationship between the porosity and pressure of open-type crack was as (6).

$$
d \phi_{f}=\frac{2 \pi \varepsilon_{f}}{3 a} d h_{f}=\frac{2 \pi \beta \alpha \phi_{f} \varepsilon_{f} h_{f}}{9 a} d P_{f},
$$

wherein, the exponential coefficient $\beta$ is assumed $0.2 \mathrm{MPa}^{-1}$ here; $a$ is the diameter of coin-type crack in Chapman (2009)[10].

The definition equation was referred to Zheng and Li (2018) [12], assuming a simulation condition with constant injection and production pressures and harmonic vibration.

\section{Simulation on the Variation of Seepage}

Referring to the crack characteristics in an oilfield in Ordos basin, the basic parameters for simulation were as Table 1. The diagram for simulation grids (with matrix pore and open-type crack) was as Figure 1. The simulation area was surrounded by injection bound, production bound and wave absorption bounds. The bound for low frequency wave stimulation was in coincidence with the injection bound.

Table 1. Basic parameters for simulation in porous media with open-type cracks

\begin{tabular}{|c|c|}
\hline Basic parameters & values \\
\hline Vibration amplitude $(\mu \mathrm{m})$ & 100 \\
\hline Vibration frequency $(\mathrm{Hz})$ & 30 \\
\hline Length of physical model $(\mathrm{m})$ & 100 \\
\hline Injection pressure $(\mathrm{MPa})$ & 12 \\
\hline Production pressure $(\mathrm{MPa})$ & 8 \\
\hline Initial pore pressure $(\mathrm{MPa})$ & 10 \\
\hline Fluid density $\left(\mathrm{kg} / \mathrm{m}^{3}\right)$ & 1100 \\
\hline Fluid viscosity $(\mathrm{mPa} \cdot \mathrm{s})$ & 1 \\
\hline Velocity of wave in fluid $(\mathrm{m} / \mathrm{s})$ & 1710 \\
\hline Density of rock matrix $\left(\mathrm{kg} / \mathrm{cm}^{3}\right)$ & 2650 \\
\hline Porosity of matrix & $15 \%$ \\
\hline Permeability of matrix $\left(10^{-3} \mu \mathrm{m}^{2}\right)$ & 50 \\
\hline Porosity of crack & $0.2 \%$ \\
\hline Permeability of crack $\left(10^{-3} \mu \mathrm{m}^{2}\right)$ & 1000 \\
\hline Radius of crack $(\mathrm{m})$ & 0.1 \\
\hline Crack width $(\mu \mathrm{m})$ & 80 \\
\hline
\end{tabular}




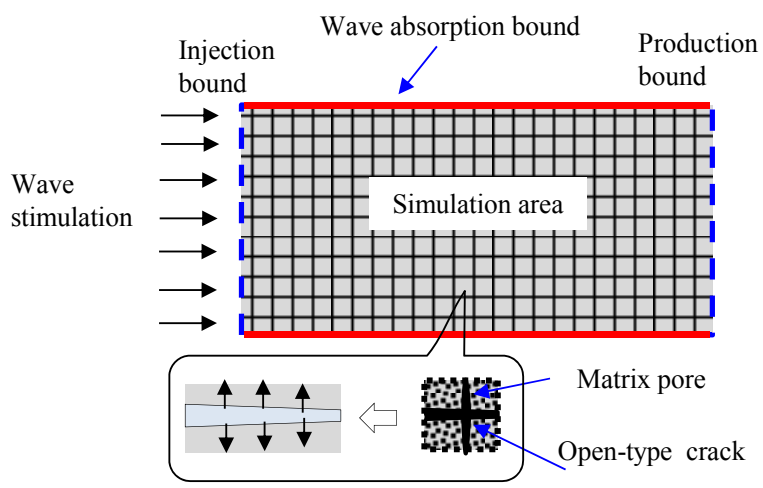

Figure 1. Physical model (virtual grids containing matrix and open-type cracks)

\section{Variation of Seepage with Chapman-Warren-Root Model}

The variation of simulated channeling rate and permeability of open-type crack was shown in Figure 2 with above mathematical model and physical model. The channeling rate and crack permeability in dual porous media with open-type crack or not were compared. An obvious difference was found with the properties.

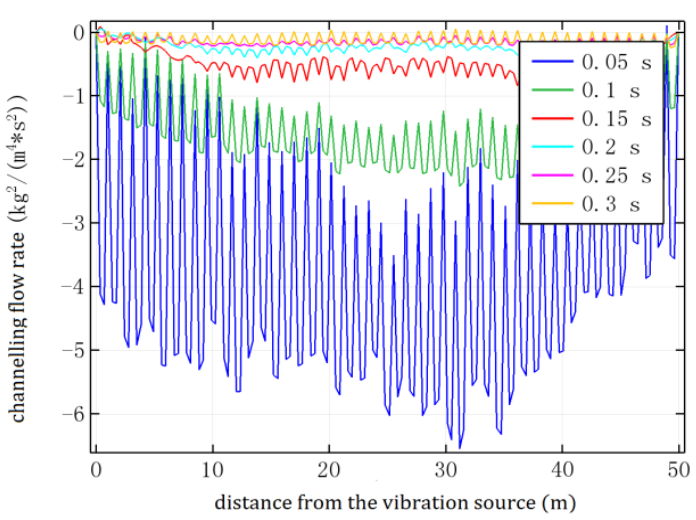

(a) channeling flow rate

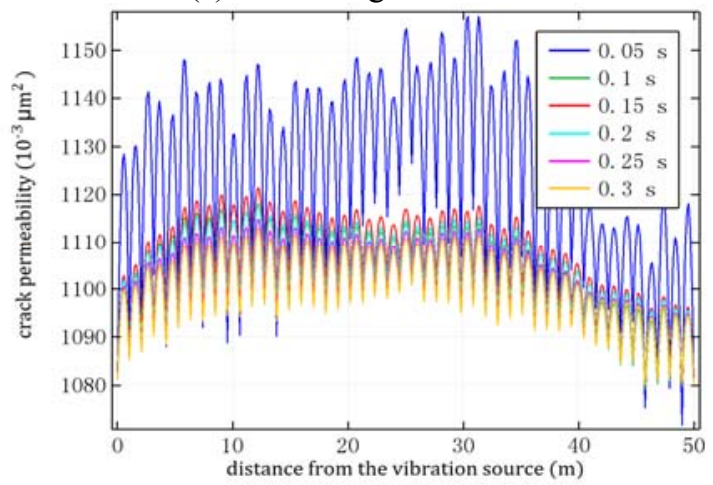

(b)crack permeability

Figure 2. Channeling flow rate and crack permeability in dual porous media with open-type $\operatorname{crack}(t \leqslant 0.3 \mathrm{~s})$

The deformation of crack, channeling flow rate between the crack and matrix pore and the average flow velocity all increased under the action of low frequency vibration oil production technology. Certainly, the stimulation effect had decreased gradually with the increase of vibration time, due to the attenuation of low frequency vibration (Ekanem et al., 2014)[13].

When the crack was open style, the raised fluid pressure inner the crack under the stimulation of low frequency vibration would lead to an obvious phenomenon as crack opening and crack permeability increasing. Then, the pressure drop in cracks decreased continually relative to that in matrix pore. The direction of channeling flow mainly kept from the crack to the matrix, and the reverse channeling flow reached the maximum at $30 \sim 35 \mathrm{~m}$ from the vibration source. 
When the crack was assumed non-open with fluid pressure (Figure 3), there exists both forward and reverse channeling between the crack and matrix pore at the same location under low frequency vibration. The value of channeling flow rate was affected by not only distance but also vibration phase. The direction of channeling was related to the vibration phase.

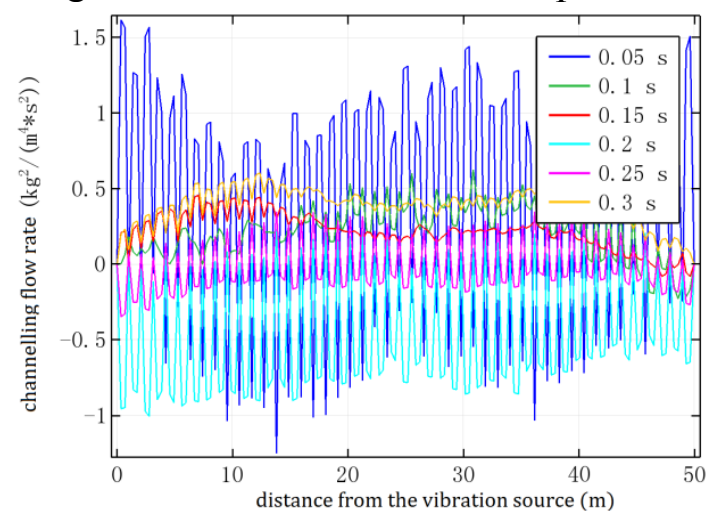

(a) channeling flow rate

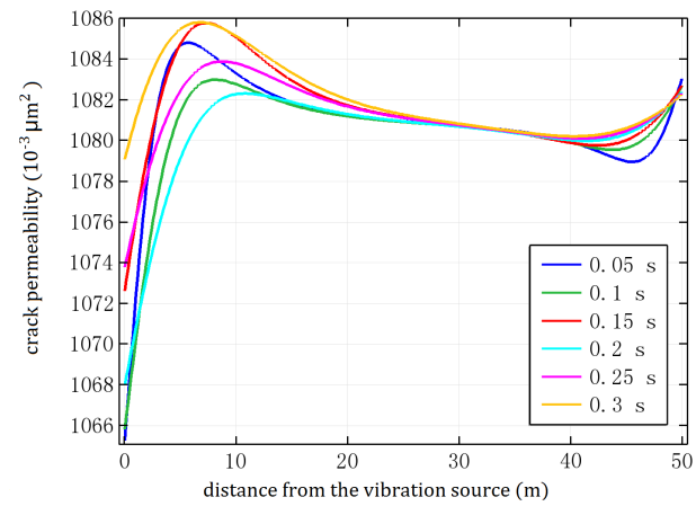

(b)crack permeability

Figure 3. Channeling flow rate and crack permeability in dual porous media only considering matrix compressibility ( $t$ $\leqslant 0.3 \mathrm{~s})$

Because the wave-induced flow had a stronger influence on the seepage field in matrix than that in crack, the direction of channeling flow was found mainly from matrix to crack. The crack permeability increased firstly and then decreased slightly with the increase of distance. With the parameters in Table 1, an obvious improvement effect existed at the distance of $8 \sim 10 \mathrm{~m}$ from the vibration source, and the improvement effect fluctuated with the vibration time increasing.

Compared with the values in figures assumed non-open-type crack, a shorter maintenance time of improving the channeling flow was found in the situation with open-type crack. Although the channeling flow in the situation with open-type crack was larger than that without considering opentype crack when the vibration time was little, the value of channeling flow was lower than the later when the at vibration time exceeded $0.2 \mathrm{~s}$. With the parameters in Table 1, the maximum value of channeling flow rate (approximately $-6.5 \mathrm{~kg}^{2} \cdot \mathrm{m}^{-4} \cdot \mathrm{m}^{-2}$ ) in the situation with open-type crack was $4 \sim$ 6 time of that without open-type crack. The maximum increase ratio of crack permeability (approximately 9.4\%) in the situation with open-type crack was about 3.3 times of that without opentype crack.

\section{Sensitivity of Exponential Coefficient for Crack Deformation}

Because the improvement effect in the areas nearby the vibration source was larger than that inner the physical model. The values for sensitivity analysis mainly chose the properties of dual porous media nearby the injection end. With the increase of exponential coefficient in the empirical equation about crack width, the maximum channeling flow rate simulated with Chapman-Warren-Root model increased firstly and then decreased in the time range of $t=0 \sim 1 \mathrm{~s}$. The largest improvement of channeling flow was got when the exponential coefficient was $0.05 \mathrm{MPa}^{-1}$. 
In contrast with the channeling rates at $1.0 \mathrm{~s}$, the inertial force of wave-induced flow had decreased and the improvement effect had become much lower because of wave attenuation. A regular rule was found with the variation of channeling flow. The channeling flow rate at 1.0s increased slightly as the exponential coefficient increased.

In addition, the maximum increase ratio of crack permeability had increased gradually with the exponential coefficient. The easier the crack was to open, the stronger the variation of crack permeability was. When the exponential coefficient was of a low value, a liner trend was found with the maximum increase ratio of crack permeability.

\section{Conclusions}

(1) A mathematical model about the seepage in porous media with open-type crack under low frequency vibration excitation was established.

(2) The deformation of crack, channeling flow rate between the crack and matrix pore and the average flow velocity all increased under the action of low frequency vibration oil production technology. The raised fluid pressure inner the crack under the stimulation of low frequency vibration led to an obvious phenomenon as crack opening and crack permeability increasing. A shorter maintenance time of improving the channeling flow was found in the situation with opentype crack, however. The largest improvement of channeling flow was got when the exponential coefficient was $0.05 \mathrm{MPa}^{-1}$ in the time range of $\mathrm{t}=0 \sim 1 \mathrm{~s}$ with the basic parameters in Table 1 . The easier the crack was to open, the stronger the variation of crack permeability was.

\section{Acknowledgment}

The authors thank the supports from the Scientific and Technological Research Project of Higher Education Institutions in Hebei Province (QN2019163), the Doctoral Funds of Yanshan University (BL17024), and a grant from Hebei Province Postdoctoral Advanced Programs (B2018003011). Thanks for the suggestions from Professor Li Zifeng.

\section{References}

[1] B.Zhang, C.S. Pu, H.R. Yu, and H.B. Sang, "Research and Application of Multi-Slug Gel Profile Control Technology in Fractured Reservoirs," Oilfield Chemistry, 2016, vol. 33, pp.46-50.

[2] S. Alexandre, M.B. Philip, D.T. Ben, F.H. Jim, and R.P. Young, "Quantifying Damage, Saturation and Anisotropy in Cracked Rocks by Inverting Elastic Wave Velocities," Pure and Applied Geophysics, 2006, vol. 163, pp.947-973.

[3] P.M. Karve, L.F. Kallivokas, and L. Manuel, "A framework for assessing the uncertainty in wave energy delivery to targeted subsurface formations," Journal of Applied Geophysics, 2017, vol. 125, pp.26-36.

[4] P. He, J.Y. Xiong, Z.H. Lu, L.H. Pan, and D.W. Qin, "Study of Pulse Wave Propagation and Attenuation Mechanism in Shale Reservoirs during Pulse Hydraulic Fracturing," Arabian Journal for Science and Engineering, 2018, vol. 43, pp.6509-6522.

[5] R. Wang, Z.P. Hu, Q.Y. Wang, X. Zhang, and Y.G. Zhang, "Spatiotemporal structures of localized traveling wave convection," Chinese Journal of Applied Mechanics, 2018, vol. 35, pp.988-995.

[6] S.K. Tong and D.L. Gao, "Mechanical principles of hydraulic pressure fluctuation injection based on fracturing technology," Oil Drilling \& Production Technology, 2018, vol. 40, pp.265-274.

[7] S.K. Tong and D.L. Gao, "Analysis of Pressure and Tip Stress in Hydraulic Fracture under Unstable Fluid Injection Condition,” China Petroleum Machinery, 2018, vol. 46, pp.65-71. 
[8] M.A. Biot, "Theory of propagati on of elastic waves in a fluid-saturated porous solid.I. lowfrequency range,” J. Acous. Soc. Ame., 1956, vol. 28, pp.168-178.

[9] J. Dvorkin, G. Mavko, and A. Nur, "Squirt flow in fully saturated rocks," Geophysics, 1995, vol. 60, pp. 97-107.

[10] M. Chapman, "Modeling the effect of multiple fracture sets of mesoscale fractures in porous rock on frequency-dependent anisotropy," Geophysics, 2009, vol. 74, pp.97-103.

[11] P. Lei, "Experimental testing theory and equipment development for interporosity flow coefficient in fractured- porous dual media," Chengdu: Southwest Petroleum University, 2014.

[12] L.M. Zheng and Z.F. Li, "Numerical Analysis of Simulation Accuracy for Seepage Change in One-Dimensional Layer Under Low-Frequency Wave," Geotechnical and Geological Engineering, 2018, vol. 36, pp.497-519.

[13] A.M. Ekanem, X.Y. Li, M. Chapman, M. Ian, and J.X. Wei, "Effect of Fracture Aperture on PWave Attenuation: A Seismic Physical Modelling Study,” Isrn Geophysics, 2014, vol. 2014, pp.1-8. 